\title{
The Research on Stress Intensity Factor of Steel Bridge Members Based on Finite Element Method
}

\author{
Ying $\mathrm{Li}^{1, \mathrm{a}}$, Jia $Q \mathrm{u}^{2, \mathrm{~b}}$ \\ ${ }^{1}$ School of Civil Engineering, ChangChun Institute of Technology, ChangChun 130012, P.R. China \\ ${ }^{2}$ Communication and Plan Designing Institue of JiLin Province, ChangChun 130021, P.R. China \\ aly_little@126.com, bqujiabox@163.com
}

Keywords: fracture mechanics, steel bridge, stress intensity factor, finite element

Abstract. The calculation accuracy of stess intensity factor $K$ has direct effect to the results when elastic fracture mechanics is adopted to fatigue life estimation. In order to decrease calculation errors, the steel I-beam with side crack and the steel box beam with central crack have been studied which are commonly used in bridge engineering, and the stress intensity factors of crack ends are calculated based on finite element method, and the results are compared with simplified formula calculating values. The conclusions have been achieved that comparative errors are obvious using empirical formulas when boundary conditions are different, and the fitting formula of shape functions are obtained based on the finite element data.

\section{Introduction}

It is regarded in fracture mechanics that defects exist in any material, and fatigue cracks originate from these defects which lead to structure damage. It has great significance for residual life estimation of existing steel bridges based on this theory ${ }^{[1]}$. Stess intensity factor $K$ is a important parameter in linear elastic fracture mechanics, and it is the main factor for fatigue life estimation whose calculation accuracy has decisive effect.

The steel I-beam with side crack and the steel box beam with central crack have been studied which are commonly used in bridge engineering, and the stress intensity factors of crack ends are calculated by finite element method ${ }^{[2,3]}$. The changing laws of stress intensity factors with different crack lengths and structure parameters are achieved and the results are compared with common simplified formula calculating values. The fitting formula of shape functions are obtained which can be used in practical engineerings.

\section{Fatigue life estimation based on fracture mechanics theory.}

Crack growth life is the main part when fracture mechanics method is adopted to predict structure fatigue life. The most commonly used crack growth formula is paris formula $\frac{\mathrm{d} a}{\mathrm{~d} N}=C(\Delta K)^{m}$. Local stress intensity factor is the key element to mesure the strength of stress and strain field and has great effect on fatigue life prediction in linear elastic fracture mechanics. The calculation accuracy has direct effect on the accuracy of fatigue life evaluation.

The stress intensity factor formulas of typical cracked body model can be got in stress intensity factor manual, but it is hard to find the results of the complex ones with complicated crack shape or loads. The finite element method, the boundary element method and the analytical method can be used to calculate stress intensity factors when conditions are complicated. It has less restriction using finite element method when the crack shape and loads are changing on the crack body, so many works have been carried in this field ${ }^{[4-7]}$. The stress intensity factors of steel I-beam with side crack and steel box beam with central crack which are commonly used in bridge engineering are the study emphasis in this paper. 


\section{Finite element model.}

Cracks in structures can be abstracted to two-dimensional or three-dimensional models, and the elastic analysis or elastic-plastic analysis has been carried out first, then the fracture parameters are calculated with special post-processing commands or macro commands.

The stress intensity factors are calculated based on 1/4 node displacement method. The singular elements are set on the front of cracks to simulate the singularity of stress-strain field on crack front. The stress intensity factors can be calculated according to $1 / 4$ node displacement of element boundary on crack front which have high precision.

The finite element models of two structures (shown as Fig. 1) are established, and the stress intensity factors on crack front of the steel I-beam with side crack and the steel box beam with central crack are calculated. Steel elastic modulus $E=2.1 \times 10^{5} \mathrm{MPa}$ and poisson ratio $\mu=0.3$ are adopted, and the axial forces are applied on structures to simulate the real force conditions of bridge structures, such as truss bridges.
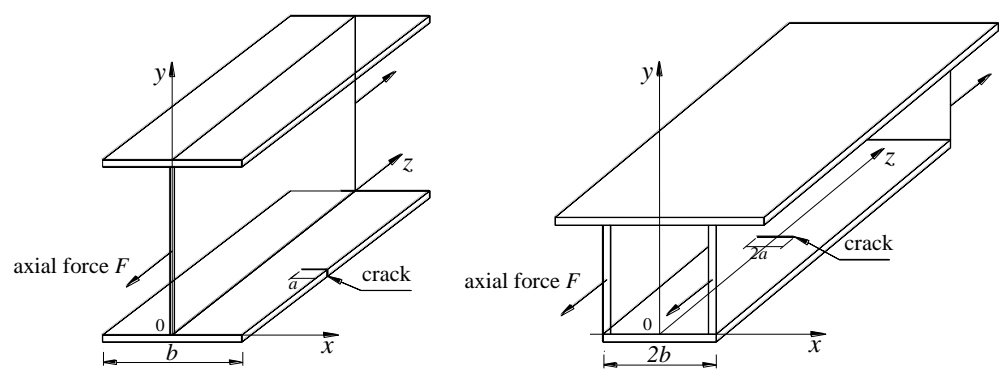

Fig. 1 Calculation structure types

Six nodes triangular elements are applied to structure top and bottom plates, and twenty nodes body elements are applied to web plates. The singular elements are set on the front of cracks, and the finite element grids and stress nephograms of crack tips are shown in figure 2 .

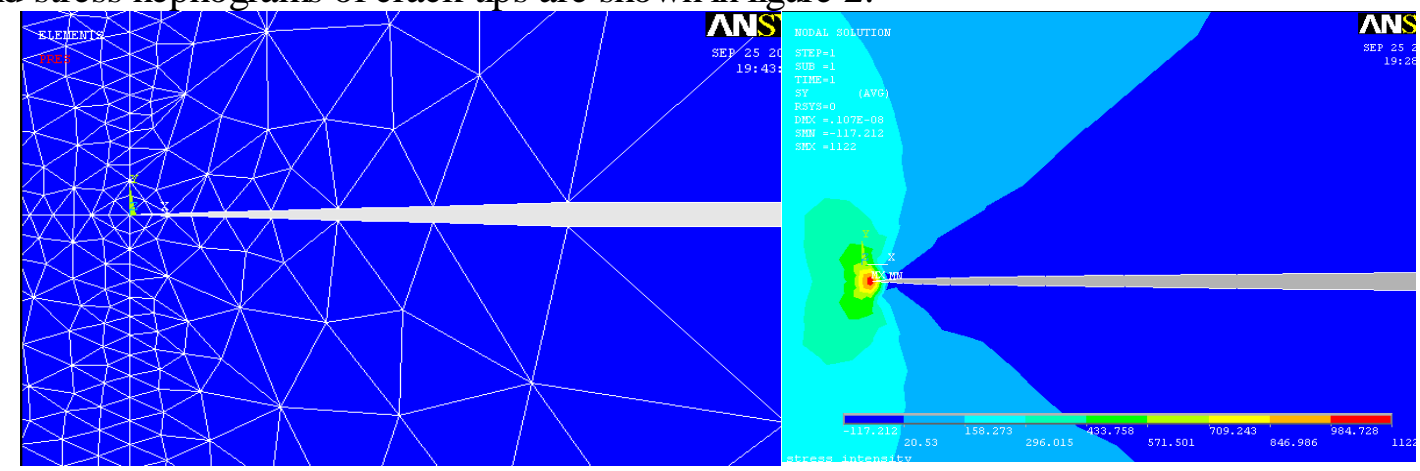

Fig. 2 Grids and stress nephograms of crack tips

\section{Calculation results and data analysis.}

Post-processing of finite element method. After the static analysis, the stress intensity factors $K_{\mathrm{I}}$ of crack tips can be calculated by post processing commands, and the shape function formulas of stress intensity factors can be got after further calculation:

$$
F(a)=K_{\mathrm{I}} / \sigma \sqrt{\pi a}
$$

Where, $\sigma$ is the stress on crack position with the same force condition when no cracks exist; $a$ is crack length.

Comparative analysis of calculation results between finite element method and simplified method. The simplified structure types which can be got in stress intensity factor manuals are often used when the stress intensity factors of complex structures with cracks need to be calculated. The differences of shape functions between simplified structures that commonly used and the accurate finite element solutions have been 
analyzed, and the corresponding regression formulas are got based on the results of finite element calculations.

Simplified models are often taken to simulate two structures with cracks involving in this research. It takes finit width steel plate with side crack to simplify steel I-beam with side crack and the finit width steel plate with central crack to simplify steel box beam with central crack, as shown in figure 3 , and the commonly used shape function formulas are as follows ${ }^{[1]}$.
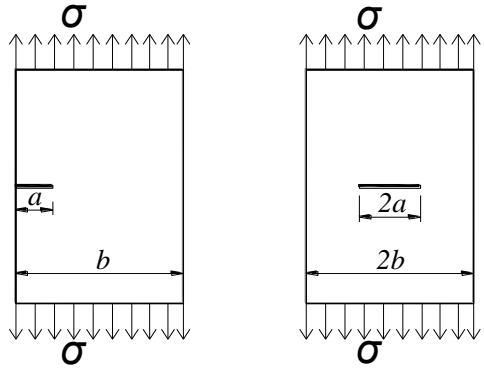

Fig.3 Simplified models commonly used

The empirical shape function formulas of finit width steel plate with side crack are:

$$
\begin{gathered}
F(a)=1.12-0.234\left(\frac{a}{b}\right)+10.55\left(\frac{a}{b}\right)^{2}-21.72\left(\frac{a}{b}\right)^{3}+30.39\left(\frac{a}{b}\right)^{4} \\
F(a)=\sqrt{\frac{2 b}{\pi a} \tan \frac{\pi a}{2 b} \cdot\left[\frac{0.752+2.02\left(\frac{a}{b}\right)+0.37\left(1-\sin \frac{\pi a}{2 b}\right)^{3}}{\cos \frac{\pi a}{2 b}}\right]}
\end{gathered}
$$

The empirical shape function formulas of finit width steel plate with central crack are:

Irwin approximate solution

$$
F(a)=\sqrt{\frac{2 b}{\pi a} \tan \frac{\pi a}{2 b}}
$$

Least squres fit of Isida formula

$$
F(a)=1+0.128\left(\frac{a}{b}\right)-0.288\left(\frac{a}{b}\right)^{2}+1.525\left(\frac{a}{b}\right)^{3}
$$

Modified Feddersen formula

$$
F(a)=\left[1-0.025(a / b)^{2}+0.06(a / b)^{4}\right] \cdot \sqrt{\sec \frac{\pi a}{2 b}}
$$

The contrast diagrams of shape functions $F(a)$ obtained by empirical simplified structures formulas and by the accurate finite element method changing with the increasing of the ratios between crack length and structure width $\mathrm{a} / \mathrm{b}$ are given in figure 4 .

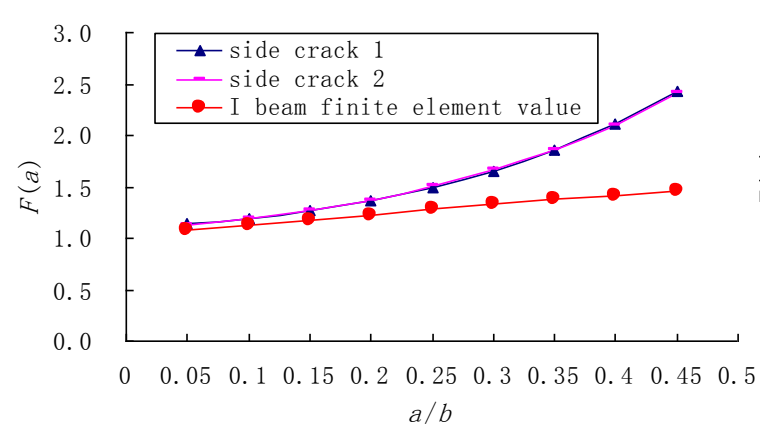

a) Edge crack

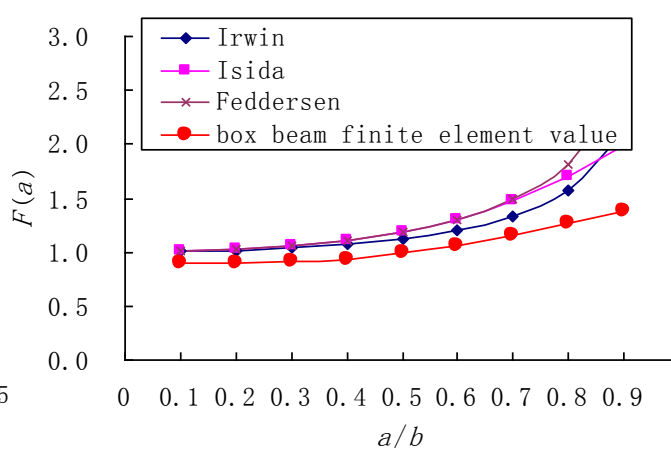

b) Center crack

Fig. 4 Calculation results contrast of geometry function $F(a)$

Calculation results analysis:

(1) The side crack 1 shown in figure 4 a) is the calculation results of formula (2), and the side crack 2 is the calculation results of formula (3). As can be seen, the shape function values based on two empirical formula are very closed, the curves are almost coincident. The shape function changing curve of steel I-beam 
with side crack based on finite element method varies gently, and the calculation values are less than the empirical formula results.

The differences are mainly for the existence of web plate which influence the boundary conditions of flange plate far from that of finit width plates, the closer the distance between crack tip with web plate the more influence can be obtained. According to the calculation results above, great errors of stress intensity factors can be got in simplifing steel I-beam flange plate with side crack as finit width plates with side crack when the ratio of crack length to flange plate width is greater than 0.3 .

(2) Irwin, Isida and Feddersen in figure4 b) are the calculation results of formula (4) to (6), which have slightly differences when the crack length is relatively long $(a / b>0.6)$. As can be seen, the shape function changing curve of steel box beam with central crack based on finite element method also varies gentle, and the calculation values are also less than the empirical formula results. the closer the distance between crack tip with web plate and the longer of crack, the larger of the difference can be obtained between finite element results and empirical formula results.

Regression formula. The multiple regression formulas of shape functions $F(a)$ changing with the ratio of crack length to structure width $a / b$ in steel I-beam with side crack and steel box beam with central crack can be got.

The regression formula of shape function to steel I-beam with side crack:

$$
F(a)=1.033+0.912\left(\frac{a}{b}\right)+0.789\left(\frac{a}{b}\right)^{2}-2.404\left(\frac{a}{b}\right)^{3}+1.865\left(\frac{a}{b}\right)^{4}
$$

The regression formula of shape function to steel box beam with central crack:

$$
F(a)=0.919-0.328\left(\frac{a}{b}\right)+0.957\left(\frac{a}{b}\right)^{2}-0.017\left(\frac{a}{b}\right)^{3}
$$

The regression effects of formula (7) and formula (8) are good, and the error ratios of the two regression formulas to finite element results are both less than $1 \%$.

\section{Summary}

The steel I-beam with side crack and the steel box beam with central crack which commonly used in steel bridges have been studied in this research. The curves of shape functions $F(a)$ changing with the ratio of crack length to structure width $a / b$ of two structures mentioned above have been got based on finite element method.

Comparative study has been carried between the finite element calculation results and the simplified empirical formula results, and the conclusions have been achieved that comparative errors are obvious using empirical formulas when boundary conditions are different. Two regression formulas of shape function have been got based on finite element calculation results to provide references for engineering use.

\section{References}

[1] LiQ F. Fracture mechanics and engineering application. Harbin: Press of Harbin Engineering University, 2004: 1 3， 252 257

[2] Wang C S, Chen A R, Chen W Z. Assessment of remaining fatigue life and service safety for old steel bridges based on fracture mechanics. China Journal of Highway and Transport. 2006, 19(2): 42 48

[3] Yang X H, Chen Z A. Investigation of fatigue life and parameters for welded steel beams. Journal of Changsha Communications University. 2006, 22(2): 12 15

[4] Xia X D, Gao R, Feng X X. Study on detection and assessment for steel truss bridge with cracking members. Steel Construction. 2007, (4): 81 83

[5] Collin Macdougall, M. F. Green, Scoott Shillinglaw. Fatigue Damage of Steel Bridge Due to Dynamic Vehicle Loads. J. Bridge Engrg. 2006, 11(3): 320 328 
[6] Yu J L, Wen T, Yan X Q, etc. Finite element analysis of stress intensity factor for straight pipes' axial semi-elliptical external surface cracks. Chemical Equipment Technology. 2012，33 (1) : 10 13

[7] Ru Z L, Shen W. An extended finite element method for calculating stress intensity factors. Journal of Henan Plytechnic University(Natrual Science). 2012，31（4）: 459-463 